18

\title{
Фотоиндуцированный перенос заряда в слоистых 2D наноструктурах $\mathrm{PbSe}-\mathrm{MoS}_{2}$
}

\author{
( И.Д. Скурлов, П.С. Парфёнов, А.В. Соколова, Д.А. Татаринов, А.А. Бабаев, М.А. Баранов, \\ А.П. Литвин
}

Центр „Информационные оптические технологии“, Лаборатория „Оптика квантовых наноструктур“, Университет ИТМО, 197101 Санкт-Петербург, Россия

e-mail: ivan.skurlov.23@gmail.com

Поступила в редакцию 28.09.2021 г.

В окончательной редакции 28.09.2021 г.

Принята к публикации 13.10.2021 г.

\begin{abstract}
Полупроводниковые 2D-наноструктуры являются новой платформой для создания современных оптоэлектронных устройств. Созданы слоистые 2D-наноструктуры $\mathrm{PbSe}-\mathrm{MoS}_{2}$, в которых наблюдается эффективный фотоиндуцированный перенос заряда от нанопластин (НП) $\mathrm{PbSe}$ к $\mathrm{MoS}_{2}$. При осаждении $\mathrm{HП} \mathrm{PbSe}$ с короткими органическими лигандами на тонкий слой НП $\mathrm{MoS}_{2}$ наблюдается уменьшение интенсивности фотолюминесценции НП $\mathrm{PbSe}$ и сокращение среднего времени затухания фотолюминесценции. При освещении слоистой 2D-наноструктуры $\mathrm{PbSe}-\mathrm{MoS}_{2}$ ИК излучением появляется фототок, что свидетельствует о вкладе $\mathrm{HП} \mathrm{PbSe}$ в электрический отклик системы. Ультратонкие слои дихалькогенидов переходных металлов, сенсибилизированные наноструктурами на основе халькогенидов свинца, могут быть использованы в фотодетекторах с расширенной в ближний ИК диапазон областью спектральной чувствительности.
\end{abstract}

Ключевые слова: нанопластины, дихалькогениды переходных металлов, перенос заряда, ближний инфракрасный диапазон.

DOI: $10.21883 / \mathrm{OS} .2022 .02 .52003 .2773-21$

Дихалькогениды переходных металлов (ДПМ) с химической формулой $\mathrm{MX}_{2}$ (где $\mathrm{M}-\mathrm{Mo}, \mathrm{W}, \mathrm{Pt}$ и др., $\mathrm{X}-$ $\mathrm{S}, \mathrm{Se}, \mathrm{Te})$ имеют слоистую структуру, в которой слои связаны друг с другом слабыми ван-дер-ваальсовыми силами и могут быть легко отделены друг от друга. При сокращении толщины до нескольких слоев происходит резкое изменение физических свойств ДПМ. Наиболее интересным является переход от непрямозонного полупроводника к прямозонному, обладающему высокими значениями коэффициента поглощения в видимой области спектра. Наряду с высокой подвижностью носителей заряда эти свойства делают ультратонкие слои ДПМ привлекательными для создания наноразмерных оптоэлектронных устройств [1].

Фотодетекторы ближнего инфракрасного (ИК) диапазона являются важным компонентом систем телекоммуникации, ночного видения, биовизуализации, экологического мониторинга и контроля пищевой продукции. На сегодняшний день изготовление таких устройств сопряжено с технологическими трудностями и высокой стоимостью производства, что ограничивает их применение [2]. 2D-материалы на основе халькогенидов металлов являются одним из наиболее привлекательных классов наноматериалов для разработки эффективных и миниатюрных фотоприемных устройств ближнего ИК диапазона $[3,4]$. Для улучшения чувствительности фотодетекторов на основе ДПМ в ближнем ИК диапазоне, необходимой для регистрации слабых сигналов, зачастую используют ИК сенсибилизаторы [5]. В качестве ИК сенсибилизаторов могут выступать, напри- мер, квантовые точки (КТ) халькогенидов свинца и ртути. Синергия свойств 0D- и 2D-наноматериалов позволяет оптимизировать сбор оптического излучения и транспорт носителей заряда [6]. Так, были получены высокочувствительные в ближнем ИК диапазоне фотодетекторы на основе ультратонких слоев $\mathrm{MoS}_{2}, \mathrm{WSe}_{2}$ и $\mathrm{WS}_{2}$, сенсибилизированных $\mathrm{KT} \mathrm{PbS} \mathrm{[7-9]}$ и $\mathrm{PbSe}[10,11]$.

Коллоидные полупроводниковые квантовые нанопластины (НП) халькогенидов металлов (CdS, CdSe, HgTe, $\mathrm{PbSe}$ и др.) являются новым классом наноматериалов с рядом уникальных физических свойств: узкие и дискретно перестраиваемые полосы оптических переходов, малый стоксов сдвиг, быстрая излучательная рекомбинация, высокая энергия связи экситона [12,13]. Уникальная геометрия и высокие значения коэффициентов поглощения НП позволяют рассматривать их в качестве перспективного сенсибилизатора для оптоэлектронных устройств, в которых они могут эффективно поглощать оптическое излучение и быть донором энергии и/или заряда [14]. Так, были изготовлены высокоэффективные фототранзисторы ближнего ИК диапазона на основе осажденного из газовой фазы монослоя $\mathrm{MoS}_{2}$ и эпитаксиально выращенных на нем $\mathrm{HП} \mathrm{PbS} \mathrm{[15].} \mathrm{Однако} \mathrm{слож-}$ ность получения таких структур исключает возможность их массового производства. Напротив, коллоидные нанокристаллы различной геометрии и химического состава, например 2D-наноструктуры ДПМ и НП халькогенидов металлов, имеют значительное технологическое преимущество. 
Для реализации эффективных фотоприемных устройств ближнего ИК диапазона на основе коллоидных НП ДПМ и халькогенидов металлов необходима оптимизация методов нанесения их тонких слоев, развитие методов обработки поверхности для сокращения расстояния между слоями и исследование процессов переноса энергии и заряда в таких структурах, определяющих эффективность устройств. В настоящей работе созданы слоистые структуры из коллоидных $\mathrm{HП} \mathrm{MoS}_{2}$ и $\mathrm{PbSe}$. Развиты методы замены лигандной оболочки $\mathrm{HП} \mathrm{PbSe}$, позволяющие минимизировать расстояние между слоями, обеспечивая эффективный фотоиндуцированный перенос заряда. Показано, что сенсибилизация слоев $\mathrm{MoS}_{2} \mathrm{HП} \mathrm{PbSe}$ приводит к увеличению фотоотклика при возбуждении системы излучением ближнего ИК диапазона.

\section{Экспериментальная часть}

\section{Методы исследования}

Спектры поглощения были измерены при помощи спектрофотометра Shimadzu UV-3600. Спектры фотолюминесценции (ФЛ) были измерены при помощи оригинального экспериментального комплекса для детектирования ИК ФЛ [16,17], спектры корректированы с использованием источника, имитирующего излучение черного тела [18]. В качестве источников возбуждающего излучения использовались лазеры с длинами волн 532 и $1064 \mathrm{~nm}$. Для исследования кинетики затухания ФЛ в качестве приемника выступал лавинный InGaAs/InP-фотодиод (Micro Photon Devices), ФЛ возбуждалась импульсными лазерами с длинами волн $532 \mathrm{~nm}$ (длительность импульса $\sim 1 \mathrm{~ns}$, частота повторения $5 \mathrm{kHz}$ ) и $1053 \mathrm{~nm}$ (длительность импульса $10 \mathrm{~ns}$, частота повторения $5 \mathrm{kHz}$ ). Микроизображения образцов были получены на сканирующем электронном микроскопе (СЭM) Merlin (Zeiss) и атомно-силовом микроскопе (АCM) Solver Pro-M (NT-MDT).

Для регистрации фотоотклика образцы наносились на стеклянные подложки с проводящим слоем ITO (Ossila), образующим электроды длиной $30 \mathrm{~mm}$ с зазором между ними $50 \mu \mathrm{m}$. Фотоотклик регистрировался пикоамперметром Keithley 2636В. Вольтамперные кривые снимались в диапазоне от -20 до $20 \mathrm{~V}$ в темноте и при возбуждении светодиодом с длиной волны $1050 \mathrm{~nm}(\sim 1 \mathrm{~mW})$ при прямом и обратном направлении изменения напряжения. Такой способ позволяет обнаружить влияние возможной асимметричности контактов образцов. Также регистрация тока проводилась при постоянном напряжении $20 \mathrm{~V}$ и периодическом включении освещения. Период освещения был равен периоду затемнения и составлял $5 \mathrm{~s}$. Для устранения влияния дрейфа измерение начиналось через $40 \mathrm{~s}$ после включения напряжения.

\section{Создание образиов}

$\mathrm{HП} \mathrm{PbSe}$ были синтезированы методом катионного обмена из НП $\mathrm{CdSe}$ толщиной 4 монослоя $[19,20]$.

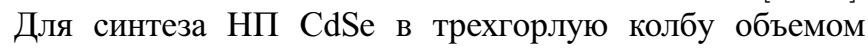
$50 \mathrm{ml}$ загружались $\mathrm{CdO}(70 \mathrm{mg}, 0.545 \mathrm{mmol})$, миристиновая кислота $(340 \mathrm{mg}, 1.49 \mathrm{mmol})$ и $27 \mathrm{ml}$ октадецена (ODE), полученный раствор дегазировался в течение $30 \mathrm{~min}$ при температуре $100^{\circ} \mathrm{C}$. По истечению данного времени колба заполнялась азотом, температура увеличивалась до $285^{\circ} \mathrm{C}$ и поддерживалась до полного растворения $\mathrm{CdO}$, что выражалось в обесцвечивании раствора. Затем колба охлаждалась до $100^{\circ} \mathrm{C}$, после чего следовала очередная дегазация для удаления воды из реакционной смеси. В течение этого времени в азотной атмосфере готовился прекурсор селена: порошок $\mathrm{Se}(24 \mathrm{mg}, 0.31 \mu \mathrm{mol})$ смешивался с $3 \mathrm{ml} \mathrm{ODE}$, после чего в течение $30 \mathrm{~min}$ подвергался воздействию ультразвука для полного растворения. После окончания повторной дегазации раствор Se вводился в трехгорлую колбу при температуре $100^{\circ} \mathrm{C}$, затем раствор подогревали до $240^{\circ} \mathrm{C}$. Рост НП запускался инжекцией $\mathrm{Cd}(\mathrm{OAc})_{2} \cdot 2 \mathrm{H}_{2} \mathrm{O}(160 \mathrm{mg}, 0.6 \mathrm{mmol})$ при температуре $195^{\circ} \mathrm{C}$. При достижении температуры $240^{\circ} \mathrm{C}$ в реакционную смесь со скоростью $25 \mathrm{ml} / \mathrm{h}$ за $10 \mathrm{~min}$ добавлялся раствор $\mathrm{SeO}_{2}(40 \mathrm{mg}, 0.36 \mathrm{mmol})$ в $5 \mathrm{ml}$ $\mathrm{ODE}$, приготовленный путем перемешивания при температуре $200^{\circ} \mathrm{C}$ до формирования чистого оранжевого раствора. После завершения инжекции колба была охлаждена с помощью водяной бани. $2 \mathrm{ml}$ олеиновой кислоты (ОА) было введено по достижении температуры $160^{\circ} \mathrm{C}$. Сепарация НП от реакционной смеси проводилась добавлением смеси гексана и этанола (3:1 по объему) с последующим центрифугированием. Выпавшие в осадок НП были перерастворены в $5 \mathrm{ml}$ толуола.

Для получения $\mathrm{HП} \mathrm{PbSe}$ в трехгорлую колбу объемом $25 \mathrm{ml}$ добавлялись $\mathrm{PbBr}_{2}(125 \mathrm{mg}, 0.34 \mathrm{mmol})$, $14 \mathrm{ml} \mathrm{ODE}$ и $2 \mathrm{ml}$ олеиламина (OlAm), реакционная смесь дегазировалась при температуре $100^{\circ} \mathrm{C}$ в течение $20 \mathrm{~h}$. По истечении данного времени температуру понижали до $80^{\circ} \mathrm{C}$, а колбу заполняли азотом. Затем происходило резкое впрыскивание раствоpa HП CdSe. Реакция катионного обмена продолжалась в течение $7 \mathrm{~h}$, после чего колба охлаждалась до комнатной температуры в водяной бане. Реакционная смесь переносилась в центрифужную пробирку, содержащую $3 \mathrm{ml}$ толуола, $12 \mathrm{ml}$ этанола и $1 \mathrm{ml}$ ОА. НП осаждались центрифугированием, надосадочная жидкость удалялась, осадок растворялся в тетрахлорэтилене $\left(\mathrm{C}_{2} \mathrm{Cl}_{4}\right)$. Спектры поглощения и ФЛ и CЭМ-микроизображения полученных $\mathrm{HП} \mathrm{PbSe}$ показаны на рис. $1, a$.

Перенос заряда между НП в слоистой структуре возможен при минимальном расстоянии между НП. Поэтому необходимо проводить процедуру замены исходной длинной лигандной оболочки из молекул ОА на более короткие лиганды. Использование коротких 

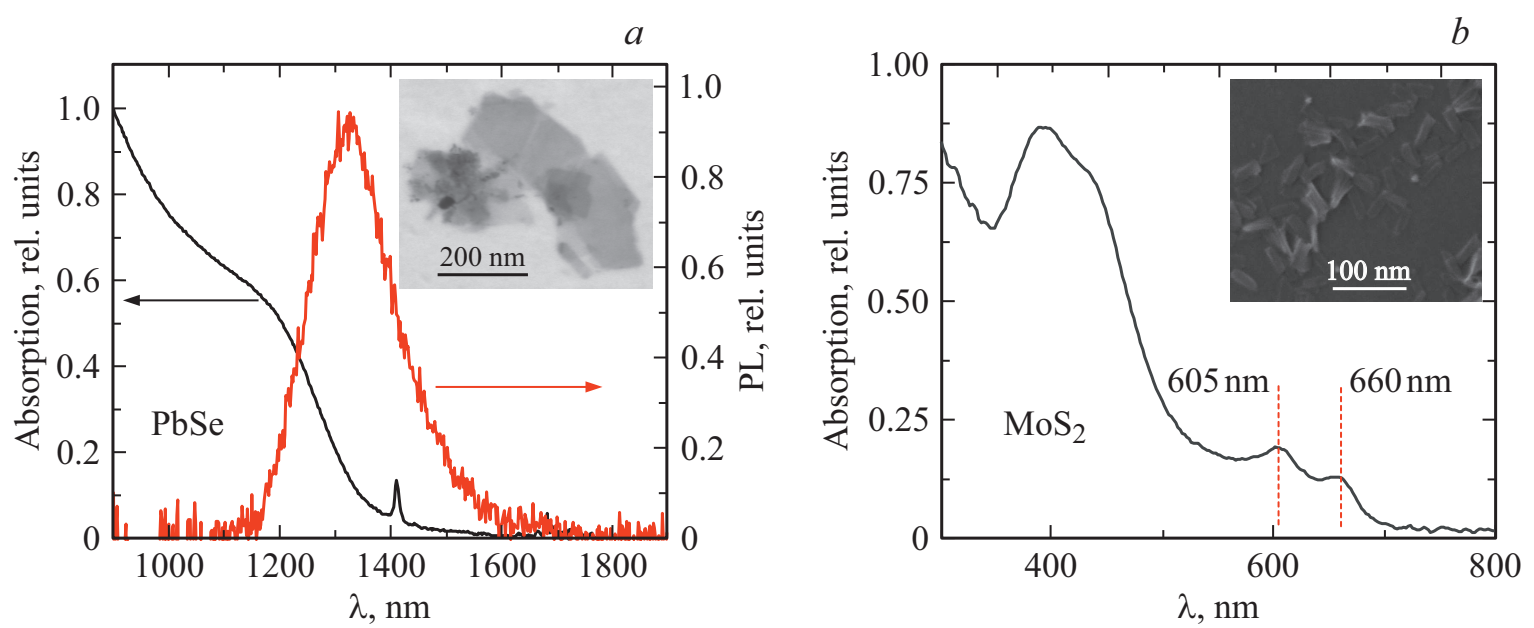

Рис. 1. (a) Спектры поглощения (черная кривая) и ФЛ (красная) НП PbSe, вставка - CЭМ-изображение HП РbSe. (b) Cпектр поглощения $\mathrm{HП} \mathrm{MoS}_{2}$, вставка - CЭМ-изображение $\mathrm{HП} \mathrm{MoS}_{2}$.

лигандов позволяет наблюдать перенос заряда в системах ИК наноструктур и НП ДПМ [21]. Для создания слоистых структур развиты методы замены лигандной оболочки $\mathrm{HП} \mathrm{PbSe}$ на более короткие органические молекулы этандитиола (EDT) и 3-меркаптопропионовой кислоты (МРА).

Замена оболочки на МРА происходила следующим образом. Стоковый раствор $\mathrm{HП} \mathrm{PbSe}$ центрифугировался при добавлении изопропанола в соотношении $1: 1$ по объему при $3000 \mathrm{rpm}$ в течение $3 \mathrm{~min}$. Выпавшие в осадок нанопластины перерастворялись в $1 \mathrm{ml}$ октана. Данный раствор НП приливался к раствору MPA $(45 \mu \mathrm{l} / \mathrm{ml})$ в диметилформамиде (DMF). Перемешивание полученного двухфазного раствора приводило к переходу НП в полярную фазу, что свидетельствовало о прошедшей замене лигандов. Оставшийся сверху октан удалялся. Для удаления остатков ОА в раствор НП-DMF добавлялся чистый октан с последующим перемешиванием и удалением октана. Далее полученный раствор НП-DMF осаждался центрифугированием при $6000 \mathrm{rpm}$ в течение 3-5 min. Для последующего нанесения выпавшие в осадок НП перерастворялись в смеси дихлорбензола и бутиламина $(5: 1$ по объему) для получения примерно такой же концентрации, как и в стоковом растворе. Нанесение пленок из $\mathrm{HП} \mathrm{PbSe}$ с оболочкой из $\mathrm{OA}$ и МРА производилось идентично. Использовался метод осаждения на вращающуюся подложку при скорости $2000 \mathrm{rpm}$.

Замена лигандной оболочки на EDT осуществлялась методом послойного нанесения тонких пленок. Исходный раствор для нанесения пленок из НП с оболочкой из ОА разбавлялся вдвое. Первый слой наносился методом центрифугирования $(2000 \mathrm{rpm})$. На полученный слой накапывался раствор EDT $(25 \mu 1 / \mathrm{ml})$ в ацетонитриле $(\mathrm{ACN})$ и выдерживался в течение $40 \mathrm{~s}$.
По истечении данного времени подложка раскручивалась для удаления раствора EDT. В течение раскрутки (60s) через равные промежутки времени $(\sim 10 \mathrm{~s})$ пленка дважды промывалась чистым ACN для удаления излишков EDT и ОА и дважды промывалась чистым гексаном для повышения адгезии последующего слоя НП. Таким образом было нанесено по два слоя.

НП $\mathrm{MoS}_{2}$ (водный раствор $0.1-0.5 \mathrm{mg} / \mathrm{ml}$ ) были закуплены в Sigma Aldrich. НП $\mathrm{MoS}_{2}$ перед использованием были последовательно центрифугированы при скоростях 1000, 2000 и $4000 \mathrm{rpm}$ для удаления агрегатов. Спектр поглощения полученной надосадочной жидкости представлен на рис. $1, b$. У исследуемых НП $\mathrm{MoS}_{2}$ наблюдается два локальных максимума поглощения на длинах волн 605 и $660 \mathrm{~nm}$ и интенсивная полоса поглощения в спектральной области $350-450 \mathrm{~nm}$, что хорошо согласуется с литературными данными [22].

Последовательное центрифугирование и удаление осадка позволяет исключить из раствора крупные агрегаты и провести селекцию $\mathrm{HП} \mathrm{MoS}_{2}$ по латеральным размерам [23]. Как видно из рис. 2, при последовательном увеличении скорости центрифугирования сокращается средний латеральный размер $\mathrm{HП} \mathrm{MoS}_{2}$. Однако слои, получаемые из фракции с НП минимального размера, не создают сплошной пленки. Поэтому для создания пленок оптимальным было использование фракции со средним латеральным размером НП $\sim 70 \mathrm{~nm}$. Для дальнейшего использования $\mathrm{HП} \mathrm{MoS}_{2}$ были нанесены на очищенные подложки методом раскапывания на разогретую подложку. После высыхания капли подложки отправлялись в муфельную печь, разогретую до $280^{\circ} \mathrm{C}$, для удаления поверхностных молекул стабилизатора. Таким образом было последовательно нанесено 5 слоев, что обеспечивало формирование тонкой непрерывной плёнки. 

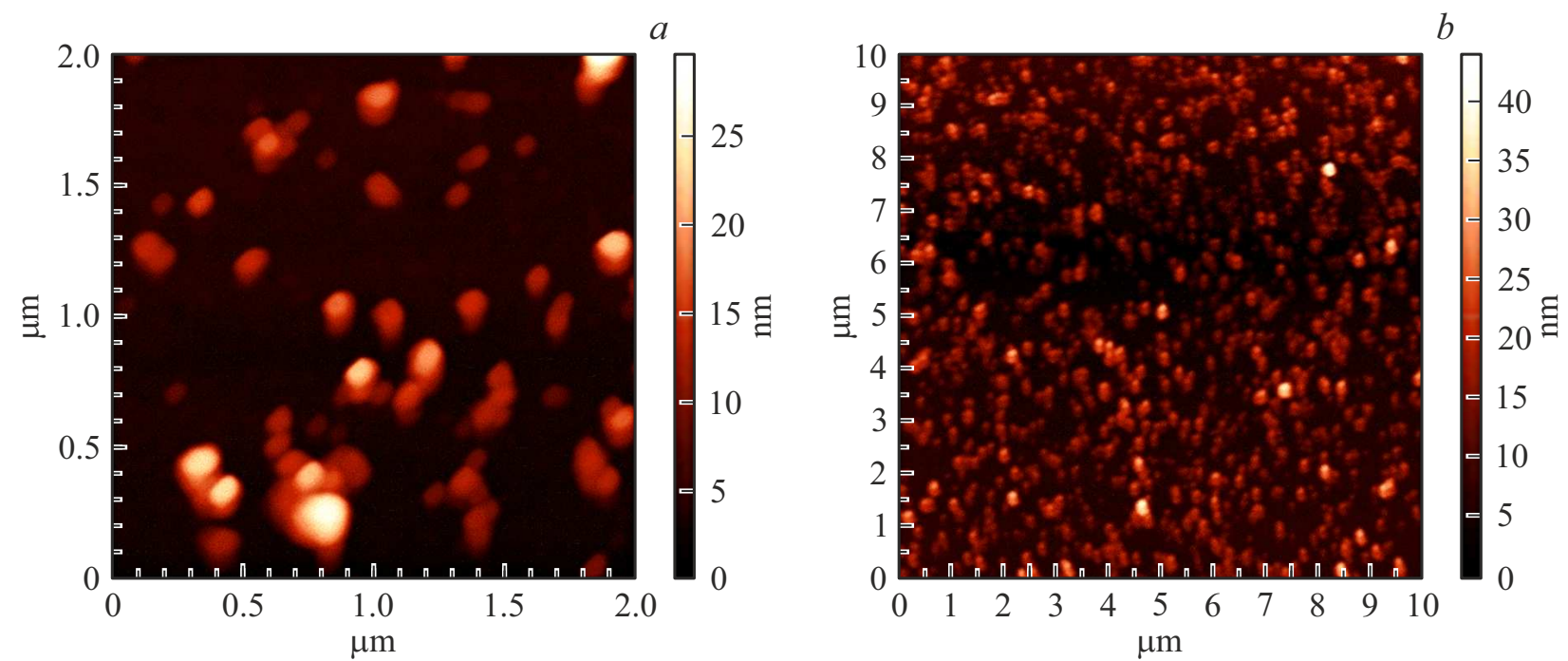

Рис. 2. АСМ-микроизображения (со шкалой высот) $\mathrm{HП} \mathrm{MoS}_{2}$, осажденных при скоростях (a) $2000 \mathrm{rpm}$ (средний размер 250 nm) и (b) $8000 \mathrm{rpm}$ (средний размер $\sim 25 \mathrm{~nm})$.
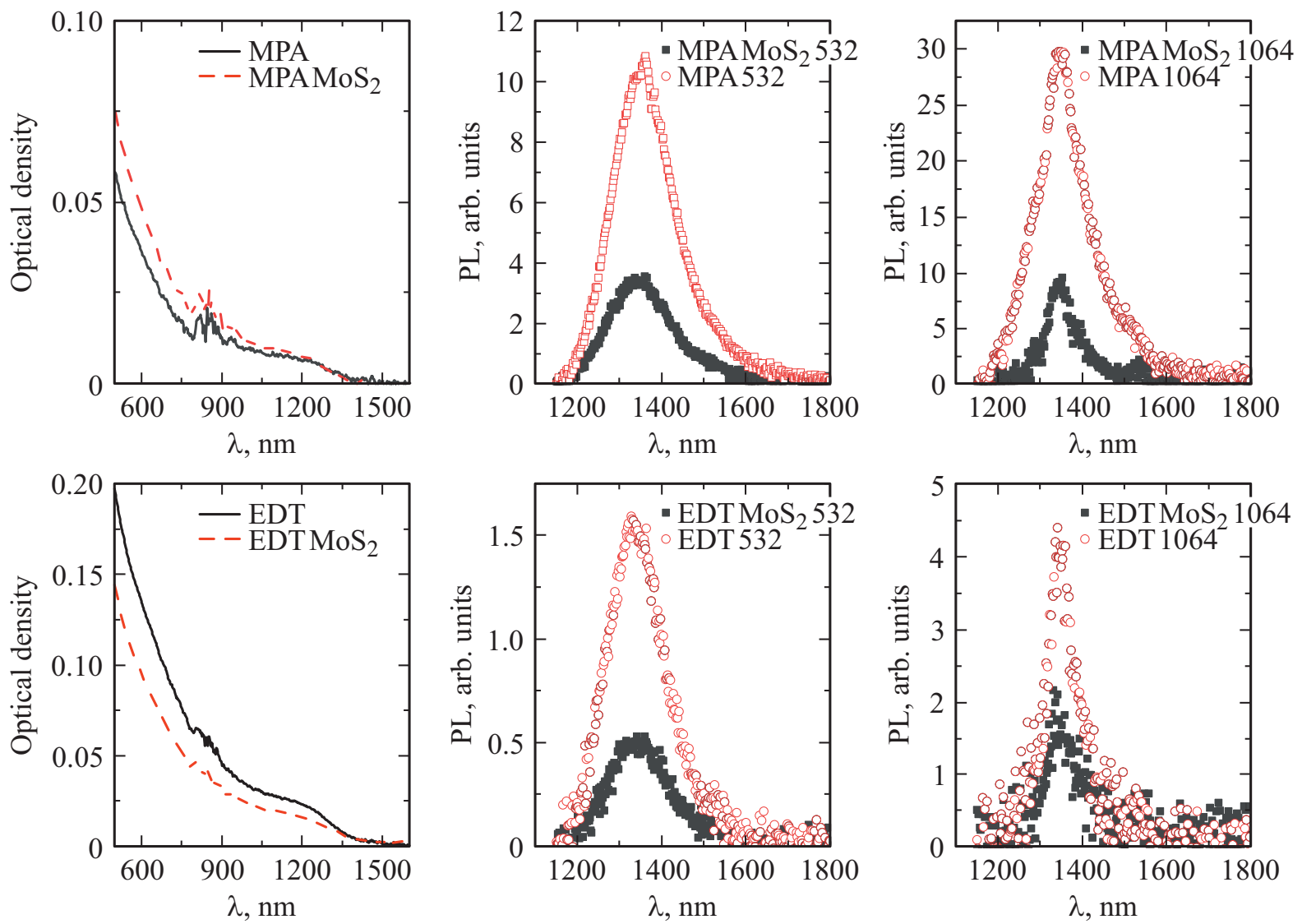

Рис. 3. Спектры поглощения и ФЛ НП $\mathrm{PbSe}$ с различной лигандной оболочкой, осажденных на стеклянную подложку и тонкий слой НП $\mathrm{MoS}_{2}$. 

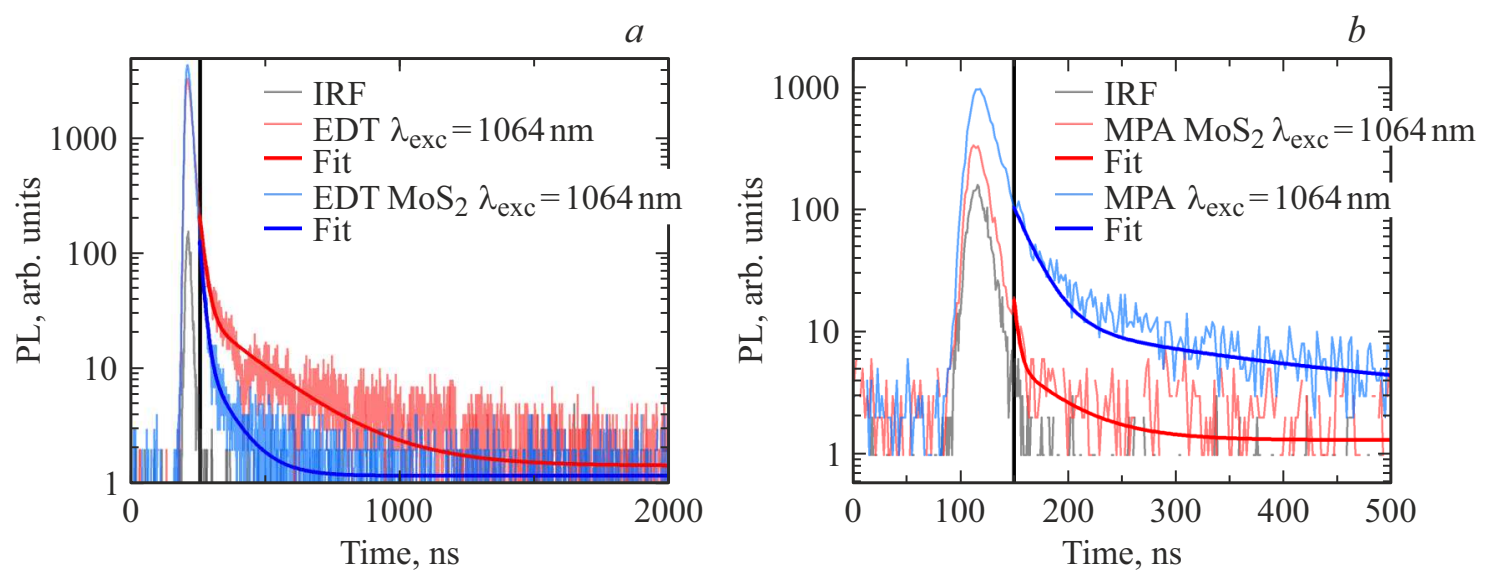

Рис. 4. Кривые затухания ФЛ НП PbSe с оболочкой из EDT $(a)$ и MPA $(b)$. Черная линия - аппаратная функция, красными и синими линиями обозначены кривые затухания ФЛ при отсутствии и наличии слоя $\mathrm{MoS}_{2}$ соответственно. Вертикальная линия показывает отсечку, после которой проводилась аппроксимация кривых затухания ФЛ.

\section{Результаты и обсуждение}

На рис. 3 представлены нормированные на оптическую плотность образцов спектры ФЛ НП $\mathrm{PbSe}$ на стеклянной подложке и на слое $\mathrm{MoS}_{2}$. Для всех образцов с короткими органическими лигандами (MPA, EDT) наблюдается тушение ФЛ как при наличии поглощения $\mathrm{MoS}_{2}$ (возбуждение на длине волны $532 \mathrm{~nm}$ ), так и при его отсутствии (возбуждение на длине волны $1064 \mathrm{~nm}$ ). Тушение ФЛ в такой структуре связано с наличием переноса заряда с $\mathrm{HП} \mathrm{PbSe}$ на слой $\mathrm{HП}$ $\mathrm{MoS}_{2}$ [21].

Более подробную информацию о переносе заряда можно получить, проанализировав кинетику затухания ФЛ НП PbSe. Кинетика затухания ФЛ была зарегистрирована на длине волны $1340 \mathrm{~nm}$ при длинах волн возбуждения 527 и $1064 \mathrm{~nm}$. Использовалась аппроксимация „хвоста“ кривой затухания ФЛ. Время отсечки было определено по окончанию лазерного импульса. Кривые затухания ФЛ при возбуждении на длине волны $1064 \mathrm{~nm}$ для $\mathrm{HП} \mathrm{PbSe}$ с различной лигандной оболочкой, осажденных на стеклянную подложку и тонкий слой $\mathrm{HП} \mathrm{MoS}_{2}$, показаны на рис. 4. Кривые затухания были описаны биэкспоненциально затухающей функцией, а в качестве среднего времени затухания было взято усредненное по амплитуде время:

$$
\tau_{\text {amp }}=\frac{A_{1} \tau_{1}+A_{2} \tau_{2}}{A_{1}+A_{2}}
$$

где $A_{i}-$ амплитуда и $\tau_{i}-$ время затухания компоненты.

Эффективность тушения была рассчитана по формуле

$$
\eta=1-\frac{\tau_{\mathrm{s}}}{\tau_{\text {glass }}}
$$

где $\tau_{\text {glass }}$ и $\tau_{\mathrm{s}}-$ времена затухания ФЛ для $\mathrm{HП} \mathrm{PbSe}$, осажденных на стеклянную подложку и тонкий слой
Времена затухания ФЛ НП PbSe с различной лигандной оболочкой, осажденных на стеклянную подложку $\left(\tau_{\text {glass }}\right)$ и тонкий слой НП $\mathrm{MoS}_{2}\left(\tau_{\mathrm{s}}\right)$

\begin{tabular}{c|c|c|c|c}
\hline Оболочка & $\lambda_{\mathrm{exc}}, \mathrm{nm}$ & $\tau_{\text {glass }}, \mathrm{ns}$ & $\tau_{\mathrm{s}}, \mathrm{ns}$ & $\eta$ \\
\hline \multirow{2}{*}{$\mathrm{EDT}$} & 532 & 103.8 & 28.6 & 0.72 \\
\cline { 2 - 5 } & 1064 & 43.8 & 20.7 & 0.53 \\
\hline \multirow{2}{*}{ MPA } & 532 & 41.0 & 8.0 & 0.80 \\
\cline { 2 - 5 } & 1064 & 37.0 & 13.0 & 0.65
\end{tabular}

$\mathrm{MoS}_{2}$ соответственно. Рассчитанные средние времена затухания ФЛ и эффективности переноса заряда приведены в таблице. Видно, что в обоих режимах возбуждения более эффективное тушение наблюдается для НП $\mathrm{PbSe}$, покрытых лигандной оболочкой MPA, что хорошо согласуется с длиной лигандов: $0.4 \mathrm{~nm}$ для МРА и $0.6 \mathrm{~nm}$ для EDT. Зависимость эффективности переноса заряда от KT $\mathrm{PbS}$ к НП $\mathrm{MoS}_{2}$ была ранее продемонстрирована в работе [21].

Для слоистых 2D-наноструктур $\mathrm{PbSe}-\mathrm{MoS}_{2}$, нанесенных на ITO-подложки, были получены вольтамперные характеристики в темноте и при освещении светодиодом с длиной волны $1050 \mathrm{~nm}(\sim 1 \mathrm{~mW})$ при прямом и обратном приложенных напряжениях. На рис. 5 показаны вольтамперные характеристики для слоистой структуры $\mathrm{HП} \mathrm{PbSe}$ с лигандной оболочкой EDT, осажденных на слой $\mathrm{MoS}_{2}$ (приведены данные с двух фоточувствительных элементов на образце). На обоих фоточувствительных элементах наблюдается появление фототока при облучении светом с длиной волны $1050 \mathrm{~nm}$, что демонстрирует вклад $\mathrm{H}$ I $\mathrm{PbSe}$ в электрический отклик слоистой структуры. На вставке показаны зависимости тока от времени для 2D-наноструктур $\mathrm{PbSe}-\mathrm{MoS}_{2}$ при использовании EDT и MPA в качестве лигандов, 


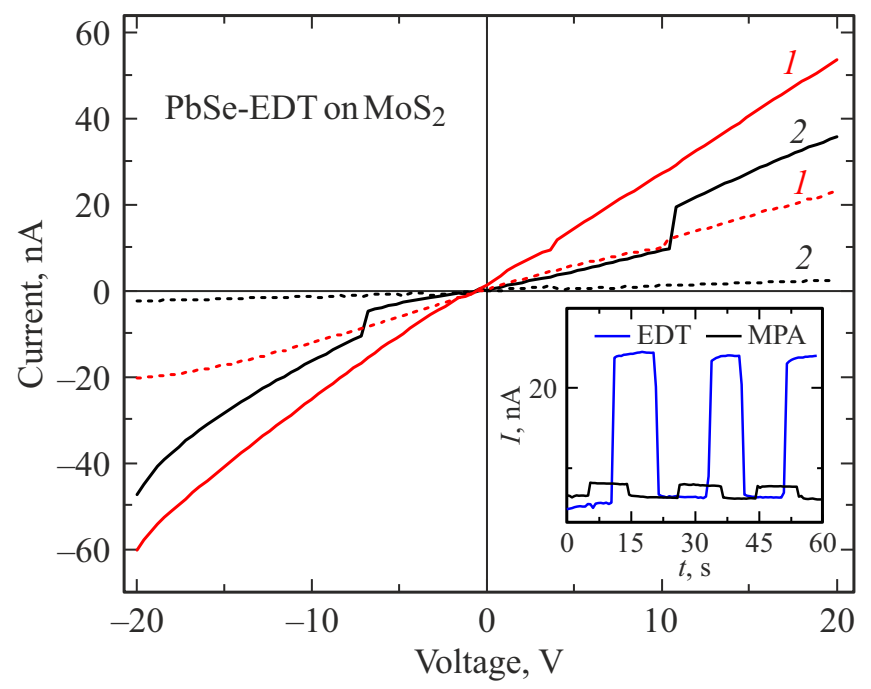

Рис. 5. Вольтамперные характеристики для слоистой структуры $\mathrm{PbSe}-\mathrm{MoS}_{2}$ с лигандной оболочкой EDT (1 и 2 - номера фоточувствительных элементов), штриховые линии - в темноте, сплошные линии - при освещении ИК светодиодом. Вставка - зависимости тока при включении и выключении ИК освещения.

демонстрирующие реакцию на свет. Стоит отметить, что более интенсивный фотоотклик получен для НП $\mathrm{PbSe}$ с лигандной оболочкой EDT по сравнению с оболочкой МРА, что может быть связано с методом формирования пленок НП $\mathrm{PbSe}$. Замена лигандов на молекулы EDT проводится методом послойного нанесения, что обеспечивает формирование более плотного слоя НП.

\section{Заключение}

Исследован фотоиндуцированный перенос заряда в слоистых 2D-наноструктурах, состоящих из коллоидных нанопластин $\mathrm{PbSe}$ и $\mathrm{MoS}_{2}$. Обнаружено тушение ФЛ и сокращение времен затухания ФЛ НП $\mathrm{PbSe}$ при нанесении их на слой $\mathrm{MoS}_{2}$, что свидетельствует о наличии фотоиндуцированного переноса заряда в данной слоистой структуре. Наиболее эффективное тушение ФЛ наблюдается при использовании более коротких лигандов МРА. Был обнаружен фотоотклик слоистых структур на ИК излучение. Наибольшее увеличение фототока также наблюдается для пленки с EDT в качестве лигандной оболочки, что обусловлено формированием плотноупакованной пленки $\mathrm{H \Pi} \mathrm{PbSe}$.

\section{Финансирование работы}

Работа выполнена при поддержке Российского фонда фундаментальных исследований (проект 20-32-90208).

\section{Конфликт интересов}

Авторы заявляют, что у них нет конфликта интересов.

\section{Список литературы}

[1] S. Manzeli, D. Ovchinnikov, D. Pasquier, O.V. Yazyev, A. Kis. Nat. Rev. Mater., 28 (2), 1-15 (2017).

DOI: $10.1038 /$ natrevmats.2017.33

[2] D. Yang, D. Ma. Adv. Opt. Mater., 7, 1800522 (2019). DOI: 10.1002/ADOM.201800522

[3] F. Wang, Y. Zhang, Y. Gao, P. Luo, J. Su, W. Han, K. Liu, H. Li, T. Zhai. Small, 15, 1901347 (2019). DOI: 10.1002/SMLL.201901347

[4] X. Zhou, X. Hu, J. Yu, S. Liu, Z. Shu, Q. Zhang, H. Li, Y. Ma, H. Xu, T. Zhai. Adv. Funct. Mater., 28, 1-28 (2018). DOI: $10.1002 / \mathrm{adfm} .201706587$

[5] C. Mu, J. Xiang, Z. Liu. J. Mater. Res., 32, 4115-4131 (2017). DOI: $10.1557 /$ jmr.2017.402

[6] D. Kufer, G. Konstantatos. ACS Photonics, 3, 2197-2210 (2016). DOI: 10.1021/ACSPHOTONICS.6B00391

[7] D. Kufer, I. Nikitskiy, T. Lasanta, G. Navickaite, F.H.L. Koppens, G. Konstantatos. Adv. Mater., 27, 176-180 (2015). DOI: 10.1002/ADMA.201402471

[8] Y. Yu, Y. Zhang, X. Song, H. Zhang, M. Cao, Y. Che, H. Dai, J. Yang, H. Zhang, J. Yao. ACS Photonics, 4, 950-956 (2017). DOI: 10.1021/acsphotonics.6b01049

[9] C. Hu, D. Dong, X. Yang, K. Qiao, D. Yang, H. Deng, S. Yuan, J. Khan, Y. Lan, H. Song, J. Tang. Adv. Funct. Mater., 27, 1603605 (2017). DOI: 10.1002/adfm.201603605

[10] J. Schornbaum, B. Winter, S.P. Schieß1, F. Gannott, G. Katsukis, D.M. Guldi, E. Spiecker, J. Zaumseil. Adv. Funct. Mater., 24, 5798-5806 (2014). DOI: 10.1002/ADFM.201400330

[11] B. Kundu, O. Özdemir, M. Dalmases, G. Kumar, G. Konstantatos. Adv. Opt. Mater., 2101378 (2021). DOI: 10.1002/ADOM.202101378

[12] M. Nasilowski, B. Mahler, E. Lhuillier, S. Ithurria, B. Dubertret. Chem. Rev., 116, 10934-10982 (2016). DOI: $10.1021 /$ acs.chemrev.6b00164

[13] E. Lhuillier, S. Pedetti, S. Ithurria, B. Nadal, H. Heuclin, B. Dubertret. Acc. Chem. Res., 48, 22-30 (2015). DOI: $10.1021 / \operatorname{ar} 500326 \mathrm{c}$

[14] B. Guzelturk, H.V. Demir. Adv. Funct. Mater., 26, 8158-8177 (2016). DOI: 10.1002/adfm.201603311

[15] Y. Wen, L. Yin, P. He, Z. Wang, X. Zhang, Q. Wang, T.A. Shifa, K. Xu, F. Wang, X. Zhan, F. Wang, C. Jiang, J. He. Nano Lett., 16, 6437-6444 (2016). DOI: $10.1021 /$ acs.nanolett.6b02881

[16] P.S. Parfenov, A.P. Litvin, E.V. Ushakova, A.V. Fedorov, A.V. Baranov, K. Berwick. Rev. Sci. Instrum., 84, 116104 (2013). DOI: 10.1063/1.4829717

[17] I.D. Skurlov, D.A. Onishchuk, P.S. Parfenov, A.P. Litvin. Opt. Spectrosc., 1255 (125), 756-759 (2018). DOI: $10.1134 / \mathrm{S} 0030400 \mathrm{X} 18110279$

[18] P.S. Parfenov, A.P. Litvin, A.V. Baranov, A.V. Veniaminov, E.V. Ushakova. J. Appl. Spectrosc., 78, 433-439 (2011). DOI: 10.1007/s10812-011-9474-1

[19] T. Galle, M. Samadi Khoshkhoo, B. Martin-Garcia, C. Meerbach, V. Sayevich, A. Koitzsch, V. Lesnyak, A. Eychmüller. Chem. Mater., 31, 3803-3811 (2019). DOI: 10.1021/acs.chemmater.9b01330 
[20] I. Skurlov, A. Sokolova, T. Galle, S. Cherevkov, E. Ushakova, A. Baranov, V. Lesnyak, A. Fedorov, A. Litvin. Nanomaterials, 10, $1-14$ (2020). DOI: 10.3390/nano10122570

[21] I.D. Skurlov, A.S. Mudrak, A.V. Sokolova, S.A. Cherevkov, M.A. Baranov, A. Dubavik, P.S. Parfenov, A.P. Litvin. Opt. Spectrosc., 128 (8), 1236-1240 (2020).

DOI: $10.1134 / \mathrm{S} 0030400 \mathrm{X} 20080330$

[22] A. Castellanos-Gomez, J. Quereda, H.P. Van Der Meulen, N. Agraï, G. Rubio-Bollinger. Nanotechnology, 27, 1-16 (2016). DOI: 10.1088/0957-4484/27/11/115705

[23] C. Backes, B.M. Szydłowska, A. Harvey, S. Yuan, V. Vega-Mayoral, B.R. Davies, P.L. Zhao, D. Hanlon, E.J.G. Santos, M.I. Katsnelson, W.J. Blau, C. Gadermaier, J.N. Coleman. ACS Nano, 10, 1589-1601 (2016).

DOI: $10.1021 /$ acsnano.5b07228 